\title{
Effects of a combined strength and high-intensity aerobic exercise program in breast cancer survivors: A pilot study
}

\author{
Jairo Alejandro Fernández Ortega ${ }^{\mathrm{a}, *}$, José Antonio de Paz Fernández ${ }^{\mathrm{b}, 1}$
}

a National Pedagogical University of Colombia, Exercise Physiology Laboratory, Colombia

${ }^{\mathrm{b}}$ Institute of Biomedicine, University of Leon, Spain

Received 4 August 2015; accepted 27 October 2015

Available online 21 December 2015

\section{KEYWORDS \\ IGF-I; \\ Breast cancer \\ survivors; \\ Quality of life; \\ Fatigue; \\ Strength exercise \\ training; \\ Physical activity}

\begin{abstract}
Introduction: The purpose of this study was to determine the effects of a combined strength and high-intensity aerobic exercise program on the quality of life (QOL), fatigue, peak oxygen consumption, strength and IGF-I in breast cancer survivors (BCSs) who had undergone surgery, chemotherapy and/or radiation therapy and were being treated with tamoxifen.

Methods: Eight BCSs followed the exercise program three times per week for 22 weeks at an intensity of $80 \%$. Herat rate reserve (HRR), strength, QOL, fatigue and insulin-like growth factor-I were evaluated.

Results: The eight participants had a $97.8 \%$ adherence rate to the training program. Increased peak oxygen consumption (20\%), increased strength $(56.9 \%)$ in the arm without lymphadenectomy (AWL), and increased strength (104\%) in the lymphadenectomy arm (AL) were observed. QOL was improved (24\%) according to the SF36 and the FACT-B scales. Both general and mood fatigue decreased $(67.7 \%)$, as did the plasma IGF-I levels $(22.8 \%)$.

Conclusions: A program of incremental strength and aerobic exercise at $80 \%$ of the HRR may be effective in improving QOL, maximum oxygen consumption, and strength and in decreasing fatigue and plasma levels of IGF-I in BCSs and does not generate or exacerbate lymphedema. (c) 2015 Consell Català de l'Esport. Generalitat de Catalunya. Published by Elsevier España, S.L.U. All rights reserved.
\end{abstract}

\footnotetext{
* Corresponding author at: Avenida Caracas \#36-18, CP 11031 Bogotá, Colombia.

E-mail addresses: jairofdz@gmail.com (J.A. Fernández Ortega), japaz@unileon.es (J.A. de Paz Fernández).

1 Campus de Vegazana S/N, 24071 León, Spain.
} 
PALABRAS CLAVE

IGF-I;

Supervivientes al

cáncer de mama;

Calidad de vida;

Fatiga;

Ejercicios de fuerza;

Actividad física
Efectos de un programa combinado de ejercicios de fuerza y aeróbicos de alta intensidad en personas supervivientes al cáncer de mama: estudio piloto

\section{Resumen}

Introducción: El objetivo de este estudio fue determinar los efectos de un programa combinado de ejercicios de fuerza y aeróbicos de alta intensidad sobre la calidad de vida, la fatiga, el consumo máximo de oxígeno, la fuerza y el IGF-I en personas supervivientes al cáncer de mama que habían sido sometidas a cirugía, quimioterapia y/o radioterapia y tratadas con tamoxifeno. Métodos: Ocho supervivientes al cáncer de mama siguieron el programa de ejercicios, 3 veces por semana durante un periodo de 22 semanas, con una intensidad del $80 \%$. Se evaluaron la reserva del ritmo cardíaco (HRR), la fuerza, la calidad de vida, la fatiga y el factor de crecimiento insulínico tipo 1 (IGF-I).

Resultados: Los 8 participantes reflejaron un índice de adherencia del $97,8 \%$ al programa de entrenamiento. Se observaron el incremento del consumo máximo de oxígeno (20\%), el incremento de fuerza $(56,9 \%)$ en el brazo sin linfadenectomía y el incremento de fuerza $(104 \%)$ en el brazo con linfadenectomía. Se produjo una mejoría de la calidad de vida (24\%) con arreglo a las escalas SF36 y FACT-B. Disminuyeron la fatiga general y el desánimo $(67,7 \%)$, al igual que los niveles plasmáticos del IGF-I (22,8\%).

Conclusiones: Un programa en el que se incremente la fuerza y el ejercicio aeróbico al $80 \%$ del HRR puede resultar eficaz para mejorar la calidad de vida, el consumo máximo de oxígeno y la fuerza, y disminuir la fatiga y los niveles plasmáticos de IGF-I, en las personas supervivientes al cáncer de mama, no generando ni exacerbando el linfedema.

(C) 2015 Consell Català de l'Esport. Generalitat de Catalunya. Publicado por Elsevier España, S.L.U. Todos los derechos reservados.

\section{Introduction}

Breast cancer is a neoplasia that requires intense and prolonged treatment with coadjuvant treatments, generating various psychological and physiological effects. These effects negatively affect the quality of life (QOL) of breast cancer survivors (BCSs) and can last for many years.

The severity and duration of symptoms depend on the type of treatment. The effects of radiation therapy, chemotherapy, and surgery are not limited to tumor cells. These treatments damage previously healthy tissues, and their effects have been correlated with fatigue, sleepiness, anxiety, and emotional stress in BCSs. Fatigue has been estimated to affect $96 \%$ of patients who receive chemotherapy treatment and $78-100 \%$ of those who have undergone radiotherapy. ${ }^{1}$ Approximately $48 \%$ of these patients present symptoms of depression and anxiety. ${ }^{2}$ Some studies have indicated that radiotherapy may be involved in myocardial interstitial fibrosis and atherosclerosis in the coronary and carotid arteries. ${ }^{3}$ Chemotherapy and radiotherapy can be linked to left ventricular function disorders due to alterations in ventricular morphology, an abnormal relationship between pressure and volume, and a decreased left ventricular ejection fraction. ${ }^{3}$ Additionally, surgery can be accompanied by axillary dissection, which together with radiotherapy, leads to a higher risk of lymphedema development.

The effects of insulin-like growth factor (IGF) on the stimulation of cell proliferation, mitosis, and apoptosis have been demonstrated and can induce the transformation of normal cells into cancerous cells and promote tumor development. ${ }^{3}$ Experiments on transgenic mice have shown that the over-expression of IGF-I leads to increased rates of mammary tumors. ${ }^{4}$ High IGF-I plasma levels are associated with increased mammographic density and tumors that carry BRCA1 mutations.

Epidemiological studies, systematic reviews, and metaanalyses of randomized controlled trials have revealed a direct association between IGF-I plasma levels and the risk of breast cancer, ${ }^{5}$ suggesting that women with high IGF-I levels or low IGFBP-3 plasma levels have higher relative risks (1.5-1.6 times) of developing breast cancer compared with women with lower levels. Pre-menopausal women with IGFI levels in the highest quartile may have twice the risk of developing breast cancer as those in the lowest quartile. Conversely, low IGF-I levels are associated with decreased cancer risk. ${ }^{6}$ Several studies have demonstrated a relationship between high concentrations of IGF-I and the risk of recurrence and death in BCSs. ${ }^{7}$

There is now ample epidemiological and experimental evidence for the role played by physical activity in the rehabilitation of female BCSs. Meta-analyses and systematic reviews of randomized clinical trials have confirmed the positive effects of physical exercise on biological and cardiopulmonary function and the reduction of sex hormones, body fat mass, insulin, IGFs, adipocytokines, and mammographic density, as well as increased immune function and improved antioxidant defense systems and QOL in BCSs. ${ }^{8,9}$

Studies conducted in rats $^{10}$ and in humans have shown that physical exercise during and after chemotherapy sessions protects the cardiovascular system from the cardiotoxic agents contained in chemotherapeutic agents (e.g., cyclophosphamide, methotrexate, 5fluorouracil, anthracycline-based drugs, and taxanes) by increasing endothelial nitric oxide synthesis and attenuating chemotherapy-induced lipid peroxidation in the myocardium. 
Physical exercise can decrease liver and muscle insulin resistance and increase glucose metabolism through a variety of mechanisms, such as increased post-receptor insulin signaling. This reduced insulin resistance may diminish circulating levels of insulin, which can in turn decrease IGF bioavailability through insulin-mediated changes in IGFBP levels. ${ }^{11}$

Additionally, physical exercise has been associated with an increased life expectancy and decreased risks of cancer recurrence and lymphedema development. ${ }^{12}$ Scientific evidence is solid and plentiful regarding the positive effect of physical exercise on QOL and fatigue in women with breast cancer. $^{13}$

Despite the extensive scientific evidence of the relationship between breast cancer and physical exercise, there is currently no consensus regarding the following variables that might be involved: exposure period, critical exposure time, intensity, frequency, and duration of physical activity. Overall, studies of physical activity and cancer have had inadequate control of intensity and volume, making exercise prescription difficult because the physiological and biological responses depend on the exercise load. ${ }^{9}$ Some studies recommend vigorous physical activity, while others propose low-intensity physical activity to reduce risk, which is not easily demonstrated given that major hormonal changes occur during high-intensity exercise.

Intense exercise has a better effect on controlling changes in estrogen metabolism, body fat mass, adipocytokines, mammographic density, immune function, and antioxidant defense systems, as well as reducing endogenous circulatory estrogen hormone levels (as cumulative exposure) and reducing glucose and insulin circulation (which can affect the levels of IGF-1 and FBP and thereby lead to decreased bioavailability of IGF-I, ${ }^{14}$ low levels of inflammatory markers, increased threshold of ACTH and cortisol secretion)-further improving physical capacity and QOL.

Scientific evidence in epidemiological studies, case control studies, systematic reviews, and meta-analyses supports the best impact of a high-intensity aerobic exercise program for reducing breast cancer risk. A review of 57 studies $^{15}$ identified a significant trend of a reduced risk of breast cancer with increasingly higher levels of physical activity. A more recent study ${ }^{16}$ in 2008, in which 34 case-control studies and 28 cohort studies were analyzed, reported a $22 \%$ risk reduction with moderate-intensity exercise and a $26 \%$ reduction with high-intensity exercise. The same evidence was analyzed in a review by the World Cancer Research Fund, ${ }^{17}$ in which an association between increased exercise intensity and decreased risk was observed. Animal studies have demonstrated that high-intensity exercise increases the life span of tumor-bearing rats by 2.8 times and reduces tumor mass by $10 \%{ }^{18}$

\section{Methods}

The study was performed in the exercise physiology laboratory at the National Pedagogical University, was approved by the Country Clinical Ethics Committee (Bogotá, Colombia), and was developed in three phases. The first phase was aimed at establishing the baseline QOL, fatigue, strength, maximal oxygen uptake, and plasma concentrations of IGF-I.
Then, the second phase consisting of an intervention program was conducted over a period of 22 weeks, with three weekly sessions of one hour each. Finally, the third phase, which took place after the end of surgery, consisted of reperforming the first-phase evaluations.

\section{Recruitment strategies and eligibility}

The group of participants consisted of women living in Bogotá (Colombia) who had been diagnosed with breast cancer, had completed the phase of chemotherapy and/or radiotherapy, had undergone a partial or total mastectomy with lymph node dissection, and were in the phase of hormonal therapy (tamoxifen) and ovarian function restriction. The recruitment for this study was conducted through a publicly advertised campaign in all oncology centers during a six-month period and at informative talks held at breast cancer patient association meetings at the Amese and Simmos foundations. Only 15 patients attended, of whom only 11 met the inclusion criteria and voluntarily participated in the study, with no economic incentive. The inclusion criteria were as follows: patients with stage 0 -III cancer who had completed radiation therapy and/or chemotherapy treatments and surgery, who were not under estrogen therapy treatment, and who were able to perform regular physical activity. Women excluded from the study included patients who had chronic uncontrolled diseases; who were taking hypotensive, diuretic, anti-inflammatory, hormonal, or lipid-lowering drugs; who were smokers or habitual drinkers; and who were participating or had participated in exercise programs over the past year.

All participants were informed of all study details and signed informed consent forms.

\section{Intervention program}

The intervention was conducted under the supervision of exercise physiology specialists, who designed a personalized exercise routine according to the physical condition of each participant. Three weekly individual and supervised sessions were conducted for a total of 22 weeks in the exercise physiology laboratory.

The aerobic workouts were performed on a treadmill (Precor 5000; Precor, Woodinville, WA, USA). The intensity was adjusted according to the heart rate reserve, as proposed by Karvonen ${ }^{19}$; the intensity was set at $60 \%$ for the first six weeks, $70 \%$ for the next six weeks, and $80 \%$ for the remaining nine weeks. Cardiac frequency was monitored with a Polar XTrainer Plus (Polar Electro, Kempele, Finland). The volume of the sessions was incremental: for the first four weeks, a duration of 20 min was used, and subsequently, the duration was increased in 5-minute increments every three weeks until reaching a duration of $50 \mathrm{~min}$. The modified Borg scale of perceived exertion was applied after completing each interval.

Due to the population characteristics, the strength program was initiated at an intensity of $10 \%$ of 1 RM based on the results of previous studies in female BCSs who had completed the adjunctive therapies and surgery. The volume was kept constant through the entire program, and two sets of 12 repetitions with a recovery of $2 \mathrm{~min}$ were performed. In 
the first six weeks the exercises were performed at $10 \%$ of maximum strength (1RM); thereafter, every four weeks, the load was increased by $10 \%$. The strength workouts included sitting arm extension, bench press, and fly.

Before and after the intervention, the following determinations were made:

Clinical history. A doctor constructed the medical history, performing an assessment of the general health status of each patient and certifying safe participation in the program. Further information on marital status, level of education, surgical technique, employment status, and the relationship with cancer type, extension, and treatments performed was recorded.

\section{QOL}

A presentation that explained in detail each of the questionnaires used to assess the QOL FACT-B, SF-36 and the fatigue PFS was conducted. After explaining each instrument and ensuring that the patients understood the purpose of the questionnaires, we proceeded to apply the instruments using a methodology for self-administration supported by trained laboratory personnel to provide keys and definitions to assist the participants when they did not understand some of the questions. It was verified that all questions were answered. Once the training program was completed, the same protocol was performed.

The Functional Assessment of Cancer Therapy (FACT-B), Spanish version, evaluates QOL perception related to health in breast cancer patients in five dimensions: physical welfare (seven sub-scales), social and family (six sub-scales), emotional (six sub-scales), functional (seven sub-scales), and health concerns. Likewise, the Short Form 36 Health Survey (SF36) was administered to evaluate physical functioning, physical role functioning, physical pain, general health, vitality, social role functioning, emotional role functioning, and mental health. Additionally, the SF-36 includes a transition item that inquires about changes in the general health status with respect to the previous year. The Piper Fatigue Scale (PFS) questionnaire quantifies fatigue according to four sub-scales (behavioral/severity, affective meaning, sensory, and cognitive/mood). These questionnaires have been used extensively to assess QOL and fatigue in breast cancer patients.

\section{Biomarkers}

Insulin growth factor IGF-I (somatomedin C): the analytical plasma concentrations of IGF-I in blood were measured by the Institute of specialized medical diagnosis (IDIME), which used the ELISA method ( $R$ \& D Human IGF-I Quantikine ELISA $\mathrm{Kit}^{\circledR}$ ) for high quality and reproducibility. The first analysis was performed before the beginning of the training program, and the second was performed $72 \mathrm{~h}$ after the last session. The two samples were taken at $8 \mathrm{AM}$ before breakfast.

\section{Physical activity}

At the beginning of the study, the participants answered two surveys: one about their physical activity levels in the last six months and another about their physical activity over the last seven days (7-day PAR).

\section{Anthropometric measures}

Body mass was evaluated with an electronic scale (Health O Meter with $50 \mathrm{~g}$ precision; Welch Allyn, Inc., Skaneateles Falls, NY, USA) and height with a height rod (Martin); body mass index $(\mathrm{BMI})$ was calculated according to the formula $\mathrm{BMI}=$ weight $(\mathrm{kg}) /$ height $(\mathrm{m})^{2}$. Bicep, triceps, sub-scapular, suprailiac, abdominal, thigh, and gastric skin folds were evaluated with a Harpenden adipometer (Baty International, West Sussex, UK), and the sum was calculated. The muscular perimeter of the arm was evaluated with a Mabis anthropometric tape. All measurements were taken twice by the same specialist according to the International Society for the Advancement of Kinanthropometry (ISAK) methodology, and the average values were recorded.

\section{Maximum dynamic strength}

The characteristics of the population and the limited information available on the assessment of maximum strength 1RM in patients with breast cancer, the method of repetitions with the equation proposed by Bryzcki 1$\mathrm{RM}=100$ reps wt was used $/(102.78-2.78$ reps. $)$ and validated in several studies.

The evaluation was conducted separately with free weights for each arm in the following movements: sitting arm extension, bench press, and fly.

The protocol began with a low load of $1 \mathrm{~kg}$. The participants performed repetitions, stopping when at least 10 tests had been performed. Then, the scale (OMNI-RES) was administered. According to the patient's assessment, the load was progressively increased by $0.5-1 \mathrm{~kg}$. The maximum force was determined when the patient was unable to perform more than eight repetitions with a load to improve the accuracy of estimating the maximum force. To avoid the effects of fatigue, rest periods of 2 min were allowed between each set.

\section{Physical function}

The estimation of V02max was performed indirectly on a Precor 5000 treadmill during a progressive and continuous workout beginning at a speed of $5 \mathrm{~km} / \mathrm{h}$ and an inclination of $6 \%$, which was increased every 2 min by $2 \%$ to exhaustion or until the participants experienced intense dyspnea, dizziness, chest pain, or an abnormal blood pressure or cardiac response. To calculate the maximum oxygen consumption, the equation proposed by the American College of Sports Medicine was used $\left(\right.$ VO2max $=3.5 \mathrm{ml} \mathrm{kg}^{-1} \mathrm{~min}^{-1}+($ vel $\mathrm{m} / \mathrm{min} \times 0.2)+(\%$ inclination $\times$ vel $\mathrm{m} / \mathrm{min} \times 1.8) .{ }^{20}$

\section{Statistical analyses}

Given the size of the sample, descriptive statistics were used to determine the effect of 22 weeks of training on the variables. The values were described as averages and 
Table 1 Baseline patient characteristics: averages and standard deviations (SDs) of the continuous variables and frequencies and percentages of the discrete variables.

\begin{tabular}{|c|c|c|}
\hline Variable & $\begin{array}{l}\text { Average } \\
n\end{array}$ & $\mathrm{SD} / \%$ \\
\hline Age (years) & 45.63 & 8.12 \\
\hline \multicolumn{3}{|l|}{ Marital status } \\
\hline Married & 7 & 87.5 \\
\hline Single & 1 & 12.5 \\
\hline \multicolumn{3}{|l|}{ Education } \\
\hline $\begin{array}{l}\text { Graduate or professional } \\
\text { degree }\end{array}$ & 3 & 37.5 \\
\hline $\begin{array}{l}\text { Some college or } \\
\text { vocational training }\end{array}$ & 5 & 62.5 \\
\hline \multicolumn{3}{|l|}{ Occupation status } \\
\hline Independent & 2 & 25 \\
\hline Housewife & 3 & 37.5 \\
\hline Employed & 3 & 37.5 \\
\hline \multicolumn{3}{|l|}{ Breast cancer stage } \\
\hline 1 & 1 & 12.5 \\
\hline IIB & 4 & 50 \\
\hline III & 1 & 12.5 \\
\hline IIIA & 2 & 25 \\
\hline \multicolumn{3}{|l|}{ Type of cancer } \\
\hline Infiltrating ductal & 7 & 87.5 \\
\hline Infiltrating lobular & 1 & 12.5 \\
\hline \multicolumn{3}{|l|}{ Surgery } \\
\hline Mastectomy & 8 & 100 \\
\hline Axillary dissection & 8 & 100 \\
\hline \multicolumn{3}{|l|}{ Treatment types } \\
\hline Radiation & 5 & 62.5 \\
\hline Chemotherapy & 7 & 87.5 \\
\hline $\begin{array}{l}\text { Chemotherapy plus } \\
\text { radiation }\end{array}$ & 5 & 62.5 \\
\hline Hormone treatment & 7 & 87.5 \\
\hline
\end{tabular}

standard deviations, as well as percentage changesusing non-parametric analysis the Wilcoxon test and significance level $(p<0.05)$ it was established.

\section{Results}

The tests to determine baseline levels were conducted in January 2013, and the intervention program ended in December 2013. Eleven patients began the program, and eight completed $97.8 \%$ of the workout sessions. Three did not complete the sessions due to exercise obligations and were not considered in the final results because it was not possible to perform the final measurements after exercise, although initial measurements were considered. None of the patients experienced adverse effects during the course of the exercise program.

Table 1 lists the sociodemographic characteristics, cancer characteristics, and types of treatment received. Tables 2-4 present the results of the morphofunctional variables, QOL, and biomarker measurements after 22 weeks of training.
After the 22-week training period, no significant decreases were observed in weight, BMI, and skinfold summation. The peak oxygen consumption exhibited a significant increase of $5.1 \mathrm{ml} / \mathrm{kg} / \mathrm{min}$. Significant increases in strength with the three types of movement occurred in both arms as follows; $2.9-3.0 \mathrm{~kg}$ BSVG and BCVG in the sitting arm extension, corresponding to increases in the maximum strength of $56 \%$ and $104 \%$, respectively. In the bench press, increases of $1.8 \mathrm{~kg}$ and $2.1 \mathrm{~kg}$ BSVG and BCVG, representing increases in the maximum strength of $42 \%$ and $101 \%$, respectively, were recorded. In the fly stroke, increases of $1.6 \mathrm{~kg}$ for the BSVG and $2.1 \mathrm{~kg}$ in the BCVG were recorded, representing increases in the maximum force of $41 \%$ and $103 \%$.

\section{QOL}

Table 3 presents the results of the QOL evaluation of the subjects before and after the training program. In the SF36, a significant reduction in the impact of the disease on QOL increased 73.1 points in the physical component and 73.7 in the mental component, corresponding to a $25 \%$ improvement in the overall QOL. The same trend was observed in the total score, which revealed that FAT-B decreased by 22.6 points, corresponding to a $24 \%$ improvement. The fatigue level also decreased by 3.8 points in the mood component and 3.6 points in general fatigue; this score was equivalent to a $68 \%$ reduction in the fatigue exhibited by these patients before beginning the training program.

Table 4 presents the changes in the IGF-I plasma concentrations before and after the training. The program led to a significant decrease of $34 \mu \mathrm{g} / \mathrm{ml}$, corresponding to a $22 \%$ reduction in the plasma biomarker IGFI.

\section{Discussion}

Increased oxygen consumption in BCSs after a training program has been reported in several meta-analyses of randomized controlled trials, which have noted significant gains $(p<0.01)$ with values between 2.2 and $3.4 \mathrm{ml} \mathrm{kg}^{-1} \mathrm{~min}^{-1}$, equivalent to increments between $13.8 \%$ and $23 \% .8,21$ In our aerobic training program, which utilized an intense split method, the same phenomenon was evident but with an average increase in oxygen consumption of $5.1 \mathrm{ml} \mathrm{kg}^{-1} \mathrm{~min}^{-1}$, equivalent to $20 \%$.

This higher value of increased oxygen consumption obtained in our study relative to the values observed in studies involving other groups might have resulted from our use of a higher-intensity exercise, which is consistent with existing evidence that this type of exercise leads to more elevated levels of peak oxygen consumption. At this intensity level, cardiovascular changes are observed, including increases in arterial elasticity, cardiorespiratory fitness, cardiac output, and arteriovenous oxygen levels, as well as decreases in the resting cardiac frequency (5.8\% or higher) and increases in oxidative enzyme levels, capillary densities, and myoglobin concentrations.

The functional and metabolic changes induced by a workout at $60 \%$ of the maximum cardiac frequency for short periods are not considered very important. ${ }^{22}$ 
Table 2 Effects of exercise training on the morphofunctional outcomes.

\begin{tabular}{|c|c|c|c|c|}
\hline Variable & $\begin{array}{l}\text { Baseline } \\
\text { Mean/SD }\end{array}$ & $\begin{array}{l}\text { Post-intervention } \\
\text { Mean/SD }\end{array}$ & $\%$ Change & $p$ \\
\hline Weight (kg) & $59.7 \pm 7.0$ & $58.3 \pm 5.5$ & -2.4 & 0.161 \\
\hline $\operatorname{BMI}\left(\mathrm{kg} / \mathrm{m}^{2}\right)$ & $25.0 \pm 3.0$ & $24.4 \pm 2.4$ & -3.1 & 0.161 \\
\hline Skin-fold sum (mm) & $166.0 \pm 36.9$ & $157.9 \pm 28.7$ & -4.8 & 0.208 \\
\hline Sitting extension arms AL (kg) & $2.8 \pm 1.2$ & $5.9 \pm 1.4$ & 104 & 0.012 \\
\hline Sitting extension arms AWL (kg) & $5.1 \pm 1.0$ & $8.0 \pm 1.0$ & 56.9 & 0.012 \\
\hline Bench press AL (kg) & $2.0 \pm 0.8$ & $4.1 \pm 1.5$ & 102.2 & 0.012 \\
\hline Bench press AWL (kg) & $4.3 \pm 1.1$ & $6.2 \pm 1.2$ & 42.1 & 0.012 \\
\hline Fly AL (kg) & $2.0 \pm 0.8$ & $4.1 \pm 1.4$ & 103.1 & 0.011 \\
\hline Fly AWL (kg) & $4.0 \pm 1.0$ & $5.7 \pm 1.0$ & 41.2 & 0.012 \\
\hline Peak oxygen consumption $\left(\mathrm{ml} \mathrm{kg}^{-1} \mathrm{~min}^{-1}\right)$ & $25.5 \pm 4.9$ & $30.6 \pm 5.7$ & 20 & 0.011 \\
\hline
\end{tabular}

Wilcoxon test and significance level $(p<0.05)$.

Table 3 Effects of exercise training on QOL.

\begin{tabular}{|c|c|c|c|c|}
\hline Variable & $\begin{array}{l}\text { Baseline } \\
\text { Mean/SD }\end{array}$ & $\begin{array}{l}\text { Post-intervention } \\
\text { Mean/SD }\end{array}$ & $\%$ Change & $p$ \\
\hline HRQL SF36 physical & $263.1 \pm 79.1$ & $336.1 \pm 47.5$ & 27.8 & 0.012 \\
\hline HRQL SF36 mental & $249.3 \pm 71.6$ & $323.1 \pm 29.8$ & 22.8 & 0.017 \\
\hline HRQL FACT-B total score & $92.6 \pm 11.7$ & $115.3 \pm 9.9$ & 24.4 & 0.012 \\
\hline PSP cognitive fatigue $/ \mathrm{mood}$ & $5.3 \pm 1.7$ & $1.5 \pm 0.7$ & -71.5 & 0.012 \\
\hline PSP fatigue/overall fatigue & $5.3 \pm 2.5$ & $1.7 \pm 0.9$ & -67.7 & 0.018 \\
\hline
\end{tabular}

Wilcoxon test and significance level $(p<0.05)$.

Table 4 Effects of exercise training on IGF-I.

\begin{tabular}{llll}
\hline Variable & $\begin{array}{l}\text { Baseline } \\
\text { Mean/SD }\end{array}$ & $\begin{array}{l}\text { Post-intervention } \\
\text { Mean } / \text { SD }\end{array}$ & \% Change \\
\hline IGF-1 $(\mu \mathrm{g} / \mathrm{ml})$ & $151.3 \pm 55.7$ & $116.8 \pm 42.5$ & -22.8 \\
\hline Wilcoxon test and significance level $(p<0.05)$. & & 0.012 \\
\hline
\end{tabular}

These higher results may also be due to an increased workload or the method used for interval training; the program was conducted entirely on a treadmill and involved the youngest in the group of patients. These factors are consistent with existing evidence suggesting that these elements have a high impact on the peak oxygen consumption.

The fractionated method has great advantages with regard to oxygen consumption. At the heart level during Smalls, the heart works at high intensity during both charging and recovery. The effort exerted by the heart in each iteration over the long term will lead to myocardial hypertrophy, whereas the rest intervals cause dilation of the atria and ventricles. The fractionated exercise also has a profound effect on the respiratory and circulatory systems (increased arterial and cardiopulmonary elasticity, cardiac output, and venous oxygen differences) to meet the oxygen demand required by the muscles.

The force is a component of the physical form, which is closely linked to health and QOL. This relationship is much more evident in the BCSs by the negative effects of adjunctive therapies and surgery. To date, no study has established a regime of resistance training with medium or high loads for BCSs, most likely because of clinical concerns regarding inducing or exacerbating lymphedema.

BCSs who have undergone lymph node dissections often experience limitations of force in the affected arm, causing difficulties lifting or carrying objects, which reduces the physical function and limits the ability to perform daily and household activities. ${ }^{23}$

Our literature review revealed very few studies that include strength programs in this population. Of 36 studies identified, only 10 implemented strength training. These data are consistent with what was found in the review of intervention programs including physical exercise in patients with breast cancer, conducted in 2010 by the ACSM, in which only 11 of 53 studies included work force ${ }^{24}$; a systematic review by Bataglini et al. ${ }^{21}$ in 2014 identified 11 studies.

These reviews indicate that in all these studies, a significant post-training program might yield an increase. This fact is confirmed in the meta-analysis conducted by Fong in $2012,{ }^{8}$ which reported significant gains in the bench press $(6 \mathrm{~kg} ; p<0.01)$, leg press $(19 \mathrm{~kg}, p<0.01)$, and $3.5-\mathrm{kg}$ grip $(p=<0.03)$. 
Our study is the first to compare the response to training of the lymphadenectomy arm versus the arm without lymphadenectomy. A better response in the lymphadenectomy arm (compared with the same training load) was observed. Our results indicate a $56.9 \%$ gain in muscle functional performance for the arm without lymphadenectomy and a $104 \%$ gain for the lymphadenectomy arm. Studies such as the investigation by Ahmed et al. ${ }^{25}$ have compared the effect of strength training on the circumference of the two arms in women with breast cancer. These results can be attributed to neuromuscular changes and/or muscular hypertrophy and have important implications for BCSs because the therapies used to treat cancer can cause peripheral nerve disruptions that are associated with muscular atrophy ${ }^{26}$ and can lead to lymphedema. Strength workouts stimulate the skeletal muscles, as well as lymphatic and venous drainage, and can exert positive effects on the sympathetic activities of vessels.

Various studies ${ }^{27}$ have reported that breast cancer and its treatments significantly affect QOL through the impairment of physical function, bodily pain, vitality, social and family roles, emotional welfare, mental health, and general health.

The results obtained in different studies and metaanalyses ${ }^{8,13}$ analyzing the effects of a physical activity program on QOL in patients with breast cancer have yielded great heterogeneity in the results. Some authors have reported significant improvements after surgery, but other authors have not. However, despite this disparity, the consensus values indicated that QOL improvement in these patients is associated with increased physical activity.

These differing results may be attributable to a variety of factors such as the methodological diversity used in each intervention, i.e., the type of exercise, intensity, frequency and duration of intervention. ${ }^{9}$

The effects of our training program on the QOL of these patients led to an overall improvement of $24.4 \%$, which was reflected in an increase of 23 points in the total score on the FAT-B scale and 73 points on the SF-36 scale-values representing a significant clinical difference (CID) considering that $\geq 9$ points is considered a CID effect. When separately analyzing the results of the components that evaluates the SF-36, a $27 \%$ increase in the physical component and a $22 \%$ increase in the mental component were observed, with a score of 85.6 in mental health, 83.1 in physical function, and 88.1 in social function, slightly higher than those identified in the meta analysis by Fong et al. The average scores of the studies analyzed for these categories were 78, 82 and 84, with average effect values of 2.4, 3.0, and 3.4, respectively.

In our intervention, a significant decrease of $67.7 \%$ was identified in the state of total fatigue, and a change of -3.51 , larger than -3 points, was considered an important CID. This positive effect of exercise on fatigue has been observed in different studies, and meta-analyses have also identified decreased fatigue and improved mood. Valenti et al. ${ }^{28}$ reported a significant effect $(p<0.001)$. Flude et al. ${ }^{29}$ obtained $p<0.001$. Cantarero et al. ${ }^{30}$ found improvements in the affective component $(F=7.347, p=0.002)$, sensory component $(F=5.199, p=0.010)$, cognitive component $(9.001$; $p=0.001)$, severity $(F=3.377, p=0.044)$, and total fatigue score $(F=10.002, p<0.001)$. Fong et al. ${ }^{8}$ observed that physical activity was associated with a slight reduction in fatigue $(-1.0,-1.8$ to $-0.1, p=0.03)$

If these findings are accurate, then all the studies show the positive effect of exercise in reducing fatigue in BCSs, but the magnitude of this effect differs.

Radiation therapy and tamoxifen consumption directly affect metabolism, leading to an increase in body fat mass that is usually between $2.5 \mathrm{~kg}$ and $11 \mathrm{~kg}$. This disruption can be maintained up to six months after treatment, affecting $50-90 \%$ of women.

The results show great heterogeneity with respect to the effect of physical activity on body weight regulation in these patients. The meta-analysis of Fong et al. ${ }^{8}$ identified reduced $(-0.4,-0.6$ to $-0.2 ; p<0.01)$ body mass index $(\mathrm{BMI})$ and reduced $(-1.1 \mathrm{~kg},-1.6$ to $-0.6 \mathrm{~kg} ; p<0.001)$ body weight after a physical activity program. These results are consistent with the meta-analysis of Speck et al. ${ }^{31}$ who also reported a significant decrease in weight $(-0.25, p=0.05)$, but this finding was not clinically important.

In our study, we observed that the training program led to a decrease of $2.4 \%$ in body weight, $3.1 \%$ in $\mathrm{BMI}$, and $4.9 \%$ in the sum of skinfolds. However, these results are not statistically significant $(p<0.16)$, nor do they represent an important clinical difference, which is consistent with the findings reported in clinical trials and meta-analyses of exercise in patients with breast cancer. ${ }^{8,21}$

This very significant reduction in body weight may be due to the combination of two effects: increased muscle mass and physical activity produces increased fat mass resulting from treatment with tamoxifen. DEXA studies have shown the impact of an AF program in patients with breast cancer in reducing fat mass. ${ }^{32}$ Moreover, the probable duration and energy expenditure of our program did not indicate that our patients would exhibit significant changes in body weight. In addition, the muscle groups used would not result in a significant change in muscle mass gained.

The decrease in fat mass causes a significantly attenuated risk of cancer recurrence due to the harmful effects of adipocytes on estrogen metabolism because toxins and drugs are stored in adipose tissue, constituting a continuous source of carcinogens. ${ }^{33}$ Studies in patients with breast cancer have demonstrated that intense exercise and fat mass loss leads to a shift in estrogen metabolism, ${ }^{34}$ and decreased metabolism of abdominal fat, particularly visceral fat, appears to be more active than fat deposits.

The results of our study revealed a decrease of $8.11 \mathrm{~mm}$ in the fold sum, equivalent to $4.8 \%$; these values are not statistically significant $(p<0.20)$ and represent an important clinical difference, which is consistent with the findings reported in clinical trials and meta-analyses of physical exercise in patients with breast cancer. ${ }^{8}$

One characteristic of breast cancer is the risk of recurrence. Hence, the necessity of tracking BCS biomarkers and IGF-I is one of multiple biomarkers for breast cancer and its impact on the etiology is proven.

Fong et al. ${ }^{8}$ in their meta-analysis of four randomized controlled trials of breast cancer, identified an association between physical activity and a significant reduction $(p<0.04)$ in the serum concentrations of IGF-I, in contrast with the non-significant results reported in previous studies. ${ }^{8}$ A case in another meta-analysis demonstrated a 
small decrease in the IGF-I levels within one year and an increase in the control group. ${ }^{31}$

Fairey et al. ${ }^{11}$ conducted a study over 15 weeks that included three 35 -minute sessions at $70 \%$ intensity per week and reported a $7.2 \%$ decrease in IGF-I in the exercise group and a $3.71 \%$ increase in the control group. The authors identified significant differences between the two groups $(-10.9 \%)$. Irwin et al. $^{7}$ reported a $3 \%$ decrease in IGF-I plasma levels in the exercise group and a $5.5 \%$ increase in the control group, representing a clinically significant difference $(p=0.089)$. The exercise program in that study comprised moderate-intensity aerobic exercise for $150 \mathrm{~min}$ per week for 24 weeks. Schmitz et al. ${ }^{32}$ in their study of a strength training program of two sessions per week for 24 weeks, did not observe any effects of exercise on IGF-I levels.

The results of these studies demonstrate the modulatory effect of physical exercise on IGF-I and IGFBP-3 plasma concentrations, suggesting that exercise causes physiological effects on IGF-I and IGFBP-3, modulates similar therapies, ${ }^{11}$ and decreases the plasma concentrations of IGF-I, thereby decreasing the risk of recurrence.

However, the effects of exercise on plasma levels of IGF$I$ and IGFBP-3 are linked to the intensity and duration of exercise.

Berg, ${ }^{35}$ in their studies on the impact of physical exercise on IGF-I, concluded that low and moderate exercise intensities lasting less than $30 \mathrm{~min}$ are associated with a moderate increase or no change in the total circulating IGFI. Conversely, exercises performed at high intensity and for a duration exceeding $45 \mathrm{~min}$ can lead to a reduction in total and free IGF-I. Further issues are linked to the time from the end of the year and the time at which the blood sample was collected, which can vary according to the anabolic and catabolic phases of IGF-I after exercise. ${ }^{35}$

A systematic review ${ }^{36}$ analyzing 115 publications regarding the effects of exercise on IGF-I in different types of populations confirms this discrepancy.

High levels of physical activity can reduce the risk of breast cancer through the insulin-signaling pathway. Exercise reduces insulin and glucose circulation, which can affect IGF-I and IGFBP levels, leading to decreased hyperinsulinemia and insulin resistance. This effect may reduce the bioavailability of IGF-I and thereby reduce the risk of breast cancer. ${ }^{14}$ One possible mechanism that has been proposed to explain this decrease in IGF-I levels is that aerobic resistance exercise can lower insulin resistance in several ways, including increased insulin receptor signaling, increased mRNA glucose transporter protein expression, increased glycogen synthase and hexokinase expression, decreased release and increased clearance of free fatty acids, increased release of glucose in the muscles due to an increase in capillary density, and a change in muscle composition to utilize this greater availability of glucose. This reduced insulin resistance may decrease the circulating insulin levels and simultaneously decrease the bioavailability of IGF-I due to increased insulin mediation, thus altering the IGBP-3 concentration. ${ }^{37}$

The scientific evidence presented shows an association between high levels of insulin and IGF-I and low levels of IGFBP-3 and an increase in the risk of breast cancer or associated death. It is therefore important to identify the factors that can reduce IGF-I levels. The responses of insulin and
IGF-I to physical exercise are key to improving the patient prognosis.

\section{Conclusions}

The results of this study indicate that high-intensity aerobic exercise combined with strength workouts three times per week for 60 min over 22 weeks has a positive effect on QOL, cardiopulmonary function, muscular function, and plasma IGF-I levels in BCSs who have undergone surgery and radiotherapy and/or chemotherapy treatments and who are receiving hormone therapy treatment.

Receiving treatments for breast cancer does not affect the ability of improved VO2max following an intensive aerobic workout, as in these patients, positive changes were observed in the chronic physiological variables after exercising.

Patients undergoing mastectomy often exhibit functional asymmetry in demonstrating the dynamics of the muscle groups acting on the shoulder and elbow, on the affected side maximum strength. As a result of strength training, improvement occurs in the demonstration of force in both upper limbs, although further improvement occurs at the tip of the affected side, which is likely to exhibit lower initial strength levels.

Physical training in women treated for breast cancer yields significantly better perceived QOL when measured with instruments to evaluate the general population and those developed to measure those affected by breast cancer. These improvements are also observed in the items exploring both physical and psychological factors.

Personalized chronic exercise improves the perception of fatigue that often affects women who are treated for breast cancer.

Moderate strength training combined with intense aerobic training in women who have undergone mastectomy for breast cancer produces a significant decrease in plasma IGF levels; this protein is used in the clinic as a biomarker of the risk of recurrence of breast cancer.

Future studies should determine the dose-response relationship, and the role of exercise in BCS should be better understood because the biological mechanisms underlying the association between physical activity and the reduction in breast cancer risk are related to exercise duration, frequency, intensity and exposure time.

Physical activity programs for survivors of cancer patients should develop strategies to achieve good adhesion to the program. $^{38}$

\section{Strengths and limitations}

According to our prior literature review, this study is one of the few that has investigated the effects of a highintensity aerobic training program on BCSs. Thus, we were able to identify a positive impact of this program on BCSs and to validate the training program methodology and monitoring. However, the study is limited by the low number of participants and the lack of a randomized controlled design, which leads to statistical power limitations with regard to the quality of the analyses and the stratification. These limitations prevent us from inferring the effects of 
the exercise program on BCSs. The present investigation is also limited because it is not a randomized controlled trial. The low number of participants was due to the conditions for program implementation. Additionally, only the IGF-I biomarker was measured, and intermediate measurements were not taken to identify the effects of exercise during the training period. Studies that involve a greater number of biomarkers, such as insulin and IGFBP-3 and its associated cytokines, should be conducted. Various measurements of these biomarkers should be obtained throughout the program's progress to identify the physical exercise duration, intensity, and frequency required to positively affect the biomarkers. Similarly, it is necessary to conduct a greater number of studies that involve different levels of intensity to permit confirmation of a dose-response effect of aerobic exercise on the levels of these biomarkers.

\section{Funding}

The research was funded by the National Pedagogical University of Colombia, there was no financial benefit to any of the authors, and neither the manuscript nor the abstract has been presented in other informative media.

\section{Conflict of interests}

Authors declare that they don't have any conflict of interests.

\section{References}

1. Burgess C, Cornelius V, Love S, Graham J, Richards M, Ramirez A. Depression and anxiety in women with early breast cancer: five year observational cohort study. Br Med J. 2005;330: 702.

2. Schultz-Hector S, Trott K-R. Radiation-induced cardiovascular diseases: is the epidemiologic evidence compatible with the radiobiologic data? Int J Radiat Oncol Biol Phys. 2007;67:10-8.

3. Azim HA, de Azambuja E, Colozza M, Bines J, Piccart MJ. Longterm toxic effects of adjuvant chemotherapy in breast cancer. Ann Oncol. 2011;22:1939-47.

4. Al-Zahrani A, Sandhu MS, Luben RN, Thompson D, Baynes C, Pooley KA, et al. IGF1 and IGFBP3 tagging polymorphisms are associated with circulating levels of IGF1, IGFBP3 and risk of breast cancer. Hum Mol Genet. 2006;15:1-10.

5. Neuhausen SL, Brummel S, Chun Ding Y, Singer CF, Pfeiler G, Lynch HT, et al. Genetic variation in insulin-like growth factor signaling genes and breast cancer risk among BRCA1 and BRCA2 carriers. Breast Cancer Res. 2009;11:1-12.

6. Xiang H, Wang Y, Nie S. Meta-analysis of the association between insulin-like growth factor binding protein 3 genetic polymorphisms and colorectal cancer susceptibility. PLOS ONE. 2013;8.

7. Irwin ML, Varma K, Alvarez-Reeves M, Cadmus L, Wiley A, Chung GG, et al. Randomized controlled trial of aerobic exercise on insulin and insulin-like growth factors in breast cancer survivors: the Yale exercise and survivorship study. Cancer Epidemiol Biomark. 2009;18:306-13.

8. Fong DYT, Ho JWC, Hui BPH, Lee AM, Macfarlane DJ, Leung SSK, et al. Physical activity for cancer survivors: meta-analysis of randomised controlled trials. Br Med J. 2012;344:e70.

9. Fernandez JA, De Paz JA. Cáncer de mama y ejercicio físico: Revisión. Hacia Promoc Salud. 2012;17:135-53.
10. Chicco AJ, Schneider CM, Hayward R. Voluntary exercise protects against acute doxorubicin cardiotoxicity in the isolated perfused rat heart. Am J Physiol. 2005;289:R424-31.

11. Fairey AS, Courneya KS, Field CJ, Bell GJ, Jones LW, Mackey JR. Effects of exercise training on fasting insulin, insulin resistance, insulin-like growth factors, and insulin-like growth factor binding proteins in postmenopausal breast cancer survivors: a randomized controlled trial. Cancer Epidemiol Biomarkers Prev. 2003;12:721-7.

12. Hayes SC, Janda M, Cornish B, Battistutta D, Newman B. Lymphoedema following breast cancer: incidence, risk factors and effect on upper-body function. J Clin Orthod. 2008;26:3536-42.

13. Bicego D, Brown K, Ruddick M, Storey D, Wong C, Harris SR. Effects of exercise on quality of life in women living with breast cancer: a systematic review. Breast J. 2009;15: 45-51.

14. Adams SA, Matthews CE, Hebert JR, Moore CG, Cunningham JE, Shu X-O, et al. Association of physical activity with hormone receptor status: the Shanghai Breast Cancer Study. Cancer Epidemiol Biomark Prev. 2006;15:1170-8.

15. Lee I-M. Physical activity and cancer prevention data from epidemiologic studies. Med Sci Sports Exerc. 2003;35:1823-7.

16. Friedenreich C, Cust A. Physical activity and breast cancer risk: impact of timing, type and dose of activity and population subgroup effects. Br J Sports Med. 2008;42:636-47.

17. World Cancer Research Fund/American Institute for Cancer Research. Food, nutrition, physical activity, and the prevention of cancer: a global perspective. Washington, DC: AICR; 2007.

18. Bacurau AV, Belmonte M, Navarro F, Morales RM, Pontes FL, Pesquero JL, et al. Effect of a high-intensity exercise training on the metabolism and function of macrophages and lymphocytes of walker 256 tumor-bearing rats. Exp Biol Med. 2007;232:1289-99.

19. Hsieh CC, Sprod LK, Hydock DS, Carter SD, Hayward R, Schneider CM. Effects of a supervised exercise intervention on recovery from treatment regimens in breast cancer survivors. Oncol Nurs Forum. 2008;35:909-15.

20. American College of Sports Medicine. Guidelines for exercise testing and prescription. 8th ed. American College of Sports Medicine; 2000.

21. Battaglini CL, Mills RC, Phillips BL, Lee JT, Story CE, Nascimento MG, et al. Twenty-five years of research on the effects of exercise training in breast cancer survivors: a systematic review of the literature. World J Clin Oncol. 2014;5:177-90.

22. Astrand P-O, Rodahl K. Precis de physiologie de léxercice musculaire. 3rd ed. Paris: Masson; 1994. p. 530.

23. Satariano WA, Ragland DR, DeLorenze GN. Limitations in upperbody strength associated with breast cancer: a comparison of black and white women. J Clin Epidemiol. 1996;49:535-44.

24. Schmitz K, Courneya K, Matthews C, Demark-Wahnefried W, Galvão D, Pinto B, et al. American College of Sports Medicine roundtable on exercise guidelines for cancer survivors. Med Sci Sports Exerc. 2010;42:1409-26.

25. Ahmed RL, Thomas W, Yee D, Schmitz KH. Randomized controlled trial of weight training and lymphedema in breast cancer survivors. J Clin Oncol. 2006;24:2765-72.

26. Cheema BSB, Gaul CA. Full-body exercise training improves fitness and quality of life in survivors of breast cancer. J Strength Cond Res. 2006;20:14-21.

27. Akin S, Can G, Durna Z, Aydiner A. The quality of life and self-efficacy of Turkish breast cancer patients undergoing chemotherapy. Eur J Oncol Nurs. 2008;12:449-56.

28. Valenti M, Porzio g, Aielli f, Verna l, Cannita l, Manno R, et al. Physical exercise and quality of life in breast cancer survivors. Int J Med Sci. 2008;5:24-8.

29. Flude ML, Groll D, Woodend K, Tranmer J. Fatigue and physical activity in older patients with cancer: a six-month follow-up study. Oncol Nurs Forum. 2009;36:194-202. 
30. Cantarero Villanueva I, Fernández Lao C, Díaz Rodriguez L, Fernández de las Peñas C, del Moral Avila R, Arroyo Morales M. A multimodal exercise program and multimedia support reduce cancer-related fatigue in breast cancer survivors: a randomised controlled clinical trial. Eur J Integr Med. 2011;3:189-200.

31. Speck RM, Courneya KS, Mâsse LC, Duval S, Schmitz KH. An update of controlled physical activity trials in cancer survivors: a systematic review and meta-analysis. J Cancer Surviv. 2010;4:87-100.

32. Schmitz KH, Ahmed R, Hannan P, Yee D. Safety and efficacy of weight training in recent breast cancer survivors to alter body composition, insulin, and insulin-like growth factor axis proteins. Cancer Epidemiol Biomark Prev. 2005;14:1672-80.

33. Hoffman-Goetz L, Apter D, Demark-Wahnefried W, Goran MI, McTiernan A, Reichman ME. Possible mechanisms mediating an association between physical activity and breast cancer. Cancer. 1998;83 Suppl.:621-8.
34. Timmer EC, De Creé C, Belgium Z. Effect of energy deficiency on estrogen metabolist in female athletes American College of Sports Medicine. Med Sci Sports Exerc. 2007;39: 1090-1097.

35. Berg U. The IGF-IGFBP system in aerobic exercise-with focus on skeletal muscle. Sweden: Karolinska Institute; 2007.

36. Orenstein MR, Friedenreich CM. Review of physical activity and the IGF family. J Phys Act Health. 2004;1:291-320.

37. Irwin ML, McTiernan A, Bernstein L, Gilliland FD, Baumgartner $\mathrm{R}$, Baumgartner K, et al. Relationship of obesity and physical activity with c-peptide, leptin, and insulin-like growth factors in breast cancer survivors. Cancer Epidemiol Biomark Prev. 2005;14:2881-8.

38. Pardo A, Violána M, Cabezas C, García J, Miñarro C, Rubinat M, et al. Effectiveness of a supervised physical activity programme on physical activity adherence in patients with cardiovascular risk factors. Apunts Med Esport. 2014;49:37-44. 